\title{
Karbon İyonlarının Beyindeki Tümör Bölgesinde Enerji Depolanmasının Monte Carlo Yöntemiyle Incelenmesi
}

\author{
Mehmet Emin KORKMAZ \\ Karamanoğlu Mehmetbey Üniversitesi, Kamil Özdağ Fen Fakültesi, Fizik Bölümü, Karaman. \\ e-posta: mkorkmaz@kmu.edu.tr ORCID ID: https://orcid.org/0000-0001-8815-5629
}

Öz

Anahtar kelimeler

Yüklü parçacık tedavisi;

Ağır iyonlar;

Kanser tedavisi;

Monte Carlo yöntemi

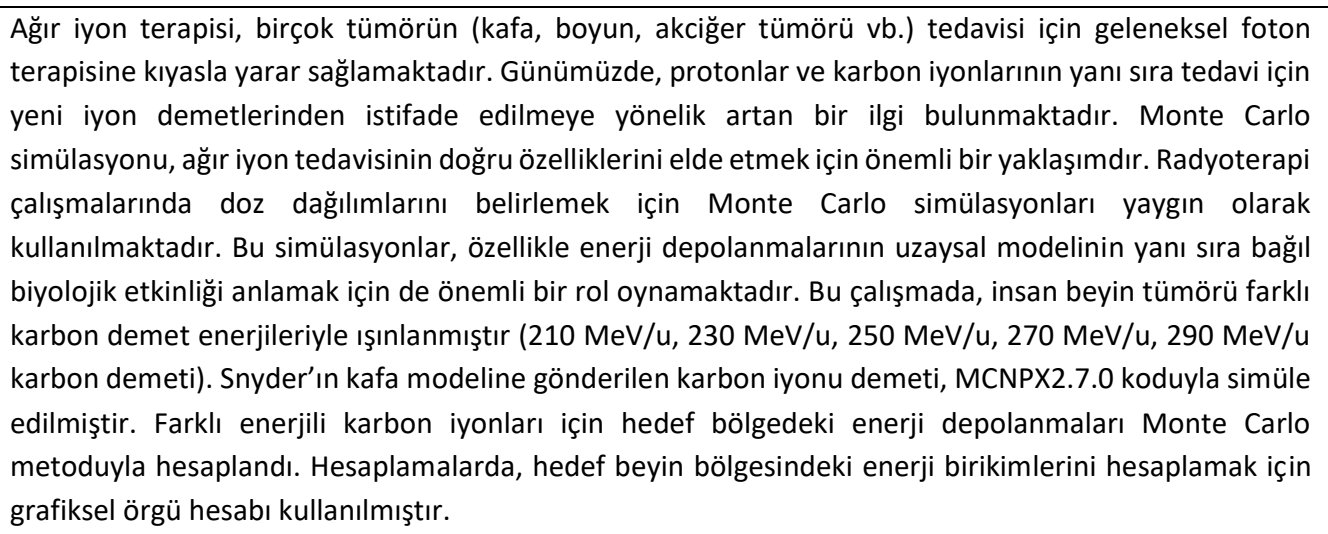

Ağır iyon terapisi, birçok tümörün (kafa, boyun, akciğer tümörü vb.) tedavisi için geleneksel foton terapisine kıyasla yarar sağlamaktadır. Günümüzde, protonlar ve karbon iyonlarının yanı sıra tedavi için yeni iyon demetlerinden istifade edilmeye yönelik artan bir ilgi bulunmaktadır. Monte Carlo simülasyonu, ağır iyon tedavisinin doğru özelliklerini elde etmek için önemli bir yaklaşımdır. Radyoterapi çalışmalarında doz dağılımlarını belirlemek için Monte Carlo simülasyonları yaygın olarak kullanılmaktadır. Bu simülasyonlar, özellikle enerji depolanmalarının uzaysal modelinin yanı sıra bağı biyolojik etkinliği anlamak için de önemli bir rol oynamaktadır. Bu çalışmada, insan beyin tümörü farkl karbon demeti). Snyder'ın kafa modeline gönderilen karbon iyonu demeti, MCNPX2.7.0 koduyla simüle grafiksel örgü hesabı kullanılmıştır.
\end{abstract}

\section{Investigation of Energy Deposition in the Tumor Region Using the Carbon Ions by Monte Carlo Method}

\begin{abstract}
Heavy ion therapy provides benefits for many tumor (head, neck, lung tumor, e.g.) treatments compared to conventional photon therapy. Nowadays there is a rising interest towards exploiting new ion beams for therapy besides protons and carbon ions. Monte Carlo simulation was an important approach to obtain accurate characteristics of heavy ion therapy. Monte Carlo simulations are widely used to determine dose distributions in radiotherapy studies. These simulations also play an important role in recognizing the spatial pattern of energy depositions as well as the relative biological activity. In this work, the human brain tumor was irradiated with a different energetic carbon beams (for 210 $\mathrm{MeV} / \mathrm{u}, 230 \mathrm{MeV} / \mathrm{u}, 250 \mathrm{MeV} / \mathrm{u}, 270 \mathrm{MeV} / \mathrm{u}, 290 \mathrm{MeV} / \mathrm{u}$ carbon beam). The incident beam of carbon ion on the Snyder's head model was simulated with MCNPX2.7.0 code. Energy depositions in the target region were calculated by the Monte Carlo method for different energetic carbon ions. In calculations, mesh tally was used to calculate energy depositions in the target brain area.
\end{abstract}

(C) Afyon Kocatepe Üniversitesi

\section{Giriş}

Kanser radyoterapisinde hadron demetleri, özellikle de proton demetleri kullanımı son yirmi yılda hızla artmıştır. Nükleer kuvvetlerle etkileşen ağır parçacık demetlerini kullanan radyoterapiye "hadron terapi" adı verilir. Hadron terapisi, proton veya daha ağır iyon demetlerinin canlı doku ile etkileşimine dayanan modern bir kanser tedavisi olup, bu yöntem kötü huylu tümör hücrelerini çevreleyen sağlıklı doku üzerinde minimal etkiler bırakarak yok edilmesini sağlamaktadır. Hadron terapide proton, nötron, helyum ve iyon (lityum, karbon, oksijen, silisyum, vb.) gibi parçacıklar kullanılabilmektedir. Standart radyasyon tedavilerine kıyasla bu tekniğin en büyük avantajı, çevredeki sağlıklı dokulara ve risk altındaki olası organlara verilen hasarı en aza 
indirgeyerek tümör bölgesinde oldukça uyumlu bir doz dağılımı sunma kabiliyetidir (Knäusl et al. 2016). Bu durum hasta dokusundaki yüklü parçacıkların tipik doz bırakma modelinden kaynaklanır ve bu da demet aralığının sonunda Bragg tepe noktasında enerji salınımında büyük bir artı̧̧ gösterir. Geleneksel X ışını ve gama ışını tedavisine kıyasla hadron terapisinin avantajlarını tam olarak anlamak için, tedavi edilen tümör boyunca Bragg tepesinin doğru konumlandırıması gerekir hadron terapisi çoğunlukla proton demetleriyle yapılmasına rağmen son zamanlarda Avrupa'da ve Japonya'da karbon demetlerinin kullanımı da başlamıştır (Traini et al. 2017, Johnson 2017).

Günümüzde hadron terapisi geleneksel radyoterapi tedavileri yerine katı tümörleri tedavi etmek için en önemli tıbbi yöntemlerden biri haline gelmektedir. Bununla birlikte, bu alandaki gelişmeler sadece hadron terapi merkezlerinin toplam maliyeti açısından değil, aynı zamanda tümör türüne ve insan vücudundaki yerini temel alan genel tedavi kalitesinin iyileştirilmesi açısından da sağlanmalıdır. İyon türleri bakımından bu tedavi tekniği için özellikle yeni ışın demetlerine yönelik çalışmalar olmasına rağmen şu anda proton ve karbon iyonları ile yapılan klinik çalışmalar bazı tür kanser tedavilerinde elde edilen sonuçlar potansiyel kullanım alanın artmakta olduğunu ortaya koymaktadır. Geleneksel radyoterapiye kıyasla hadron terapisinin üstünlüğü, , yüklü parçacıkların enerjilerinin çoğunu nüfuz etme aralığının sonuna yakın birkaç milimetre (Bragg tepe bölgesi) arasında bırakması gerçeğinden kaynaklanmaktadır. Bu tür önemli özellikler yalnızca tümör hücrelerine hasar verir ve tümör bölgesini saran sağlıklı dokularla sınırı olarak etkileşerek en az zararı verir. Karbon iyonları protonlara kıyasla Bağıl Biyolojik Etkinliğin (RBE) belirgin bir şekilde artmış olması radyoaktif tedaviye dirençli tümörlerin çoğunda daha etkili bir tedavi olduğunu göstermiştir(Mein et al., 2018). Öte yandan karbon iyon demetinin hedef bölgede nükleer parçalanma oluşturmasının bir dezavantajı vardır. Ortaya çıkan düşük enerjili parçacıklardan dolayı bir miktar enerji, Bragg zirvesinin ötesinde istenmeyen doz birikmesine neden olmaktadır. Bu özellik muhtemelen alınan dozun düşük olmasından dolayı klinik olarak önemli değildir. Ortaya çıkan karışık alanın nükleer parçacıkları, nihayetinde kanser dokularına bırakılan biyolojik dozun belirsizliğini arttırır(Durante et al. 2016, Schardt et al. 2010). İyon demeti tedavisinde karbon iyonlarına potansiyel bir alternatif de oksijen iyonlarıdır. Artan lineer enerji transferi, göreceli olarak daha yüksek bir biyolojik etkinlik ve azaltılmış oksijen arttırma oranını göstermektedir (Resch et al. 2017).

Beyin tümör tedavisinde önemli çaba ve ilerlemelere rağmen, bazı tümörler agresif olabilir. Bu yüzden yüksek dereceli tümörlü (high-grade gliomas) hastalara karbon iyonu radyoterapi önerilmektedir(Combs et al. 2013). Karbon demetleri ile ışınlama, komşu organları aynı anda riske sokarken aynı zamanda biyolojik etkinliğin artmasıyla birlikte çok hassas doz verilmesini sağlayan çok farklı radyobiyolojik ve radyofiziksel etkiler ortaya koymaktadır. Günümüzde radyoterapi, beyin kanseri hastalarının tedavisinde standart olan cerrahi ve kemoterapiyle birlikte kullanılmaktadır. Yoğunluk ayarlı radyoterapi ve sterotaktik radyoterapi gibi modern radyasyon terapi teknikleri, tümör hedefine doza uygunluk ve çevredeki kritik yapılara minimum doz vermeyi sağlamaya çalışmaktadır. Primer beyin tümörleri olan hastalarda yüklü parçacık terapisi güvenli ve uygundur. Proton ve karbon ile radyoterapi dünyanın bazı araştırma ve tedavi merkezlerinde çalışmaya başlamıştır. Almanya'da Heidelberg İyon Terapi Merkezi (HIT), 2009 yılının Kasım ayında hasta tedavisine başlamış ve şu ana kadar 250'den fazla hastaya baş ve boyun tümörleri olmak üzere primer beyin tümörlerini tedavi etmiştir (Rieken et al. 2012). Parçacık Terapisi İşbirliği Grubu (PTCOG) verilerine göre dünya çapında karbon iyonlarıyla 2016 yılının sonu itibariyle 21580 hasta tedavi edilmiştir (Int Kyn. 1).

Sınırlı miktarda iyon demetlerinden dolayı Monte Carlo (MC) transport kodları (GEANT4, MCNPX, FLUKA vb.), bu iyonların etkilerini araştırmak için önemli araçlardır. Monte Carlo modellemesi, medikal fizik alanında tedavi planlaması, dedektör düzeltme faktörlerinin oluşturulması, hızlandırıcı tasarımı ve dedektör tasarımında giderek daha fazla 
önem kazanmıştır. Bu çalışmada, hızlandırılan karbon iyonlarının insan kafa modelinin hedef bölgesinde bıraktıkları enerjiler Monte Carlo yöntemi ile hesaplanmıştır.

\section{Materyal ve Metot}

\subsection{Yüklü Parçacıkların LET ve RBE'si}

Lineer Enerji Transferi (LET), bir iyonlaştırıcı radyasyon madde içinde ilerledikçe birim mesafe ( $d E / d x)$ başına enerji kaybının fonksiyonudur ve bağıl biyolojik etkinlik (RBE=Dreferans/Dhadron) ile korelasyon gösterir. Işınım yaparak enerji kaybının (Bremsstrahlung) etkilerini içermediği sürece durdurma gücüne benzerdir. Bağıl biyolojik etkinlik değeri, tanımlanmış bir biyolojik etkiyi aynı derecede oluşturan soğurulmuş dozların oranıdır. Eşit dozlarda fakat farklı nitelikte ve türdeki ışınımların yolları boyunca lineer enerji transferleri farklı değerde olması nedeniyle biyolojik etkileri farklıdır. Herhangi bir ışınımın biyolojik etkisi LET'i ile artmaktadır.

Ağır yüklü parçacık demetleri, madde boyunca ilerlediklerinde çok farklı RBE'ler göstermektedir. Protonlar doza göre nispeten lokalize biyolojik hasara neden olurken, ağır yüklü parçacık demetleri geçtikleri yol boyunca birçok iyon izi üretmekte ve böylece yerel olarak çoklu hasarlara neden olmaktadır. Aslında ağır iyon demetleri için radyobiyolojik etkiyi kapsayan LET'den daha ziyade iyon demetlerinin iz yapısını anlamak gereklidir (Park and Kang 2011).

Karbon iyonu demetlerinin etkililiği ile ilgili olarak, gerek sistematik deneysel araştırmalar gerekse normal doku modellerinde yapılmış ve farklı tümör tiplerinin karbon iyon demetlerine cevabı üzerine çok az nicel veri şu anda mevcuttur. Foton radyoterapisi için tedavi planlamasında olduğu gibi, tümörler halen biyolojik olarak homojen varlıklar olarak kabul edilir ve bağıl biyolojik etkinlik (RBE), RBE'nin doğrusal enerji aktarımına (LET) ve doz bağımlılıklarını ayarlamak için biyomatematik modeller kullanılarak hesaplanır.

Tümörün biyolojik yanıt karakteristikleri, ek tümör ile ilişkili biyolojik faktörlerin RBE üzerindeki etkisini inmal eden çok az parametre ile tanımlanmaktadır. Bununla birlikte, fotonlar ve iyon demetleri için tümör tepkisini farklı şekilde etkileyen herhangi bir parametrenin RBE'yi etkilemesi beklenmektedir. Bu nedenle, tümörlerin iyon demetlerine yanıtını daha iyi anlamak için, bu bağımlılıklar sistematik klinik öncesi deneylerde nicel olarak tanımlanmak ve değerlendirilmek zorundadır (Glowa et al. 2017, IAEA TRS-461, 2008).

\subsection{Grafiksel Örgü (mesh) Hesabı}

Monte Carlo simülasyonları, radyoterapi alan hastalarda tüm vücuttaki doz dağılımlarını düzenlemek için kullanılmaktadır. Çünkü bu simülasyonlar ayrıntılı ve doğru alan dışı dozimetrik sonuçlar vermektedir. Los Alamos Ulusal Laboratuvarı tarafından geliştirilen genel amaçlı radyasyon taşınım kodu MCNPX (Monte Carlo NParticle eXtended) (Pelowitz 2011), hadron tedavisinde birincil ve ikincil dozları simüle etmek için radyoterapi araştırma uygulamalarında yaygın olarak kullanılmaktadır. Ancak, karmaşıklık ve uzun simülasyon sürelerinden dolayı tüm vücut doz incelemeleri için aşılması gereken zorluklar bulunmaktadır (Zhang et al. 2013).

Grafiksel örgü hesabı, standart problem geometrisinin üzerine yerleştirilmiş dikdörtgen, silindirik veya küresel bir bölge üzerinde parçacık akı, doz veya diğer miktarların grafiksel olarak görüntülenmesi için bir yöntemdir. Doz dağılımlarını hesaplamak için MCNPX'de en sık kullanılan yaklaşım, problem geometrisi üzerine yerleştirilmiş yapay bir ızgarada belirli bir bölge alanını inceleme yöntemi olan örgü (mesh) grafik hesabıdır. Ancak, bu yöntemde de parçacıkların izlenmesi ve hesaplamalar için uzun simülasyon süreleri gerekmektedir.

Grafiksel örgü hesabı, sonuçların görselleştirilmesi için kullanışlıdır. Özellikle, MCNPX grafik kabiliyeti, problem geometrisi üzerinde üst üste bindirilmiş örgü hesabı sonuçlarının çizilmesini mümkün kılar. Grafiksel örgü hesabı hesaplamalarda yavaştır, çünkü parçacık aktarımındaki her adımda bindirilmiş örgü hesabı içindeki konum bulunmalıdır. Alternatif 
bir yaklaşım, MCNPX'deki tekrarlanan yapı özelliklerine dayanan kafes hesabıdır. Bununla birlikte, nispeten az sayıdaki yayınlanmış çalışma, proton radyoterapi uygulamaları için kafes simülasyonunu kullandığını bildirmiştir. Bu nedenle, karbon terapisinde tüm vücut doz hesaplamalarında Monte Carlo simülasyon sürelerini azaltmak için kafes simülasyonları da kullanılabilir.

MCNPX kodu içerisinde parçacık ve ağır iyon demetlerinin özelliklede karbon demetinin hedef beyin bölgesinde enerji depolanmalarını görmek için giriş dosyasında grafiksel örgü hesabını tanımlayan kartlar bulunmaktadır. Giriş dosyası içindeki 1. tipteki grafiksel örgü hesabında kullanılan PEDEP kartı birim hacim başına ortalama enerji depolanmasını (MeV/cm3/kaynak parçacık) sonuçlarını vermektedir.

\section{Bulgular}

Karbon demeti iletim sistemini ve beyin bölgesini modellemesi MCNPX2.7.0 kod versiyonunda yapılmıştır. Karbon kaynağı demetinin özelliği, nükleon başına $\mathrm{MeV}$ enerjisinde $(\mathrm{MeV} / \mathrm{u}$ ) ve $\mathrm{z}$ ekseni doğrultusunda, $2 \mathrm{~cm}$ yarıçapında dairesel olarak $(0,0,15) \mathrm{cm}$ koordinatında belirlenmiştir. Tümör bölgesine gönderilen karbon demeti enerjileri 210 $\mathrm{MeV} / \mathrm{u}, 230 \mathrm{MeV} / \mathrm{u}, 250 \mathrm{MeV} / \mathrm{u}, 270 \mathrm{MeV} / \mathrm{u}$ ve 290 $\mathrm{MeV} / \mathrm{u}$ olarak seçilmiştir. MCNPX'de hedef bölgede enerji depolanmasının hesaplaması için grafiksel örgü (mesh tally) hesabı kullanılmıştır. Kafa bölgesinde karbon demetinin meydana getirdiği reaksiyonlar sonucu enerji depolanması ( $\mathrm{MeV} / \mathrm{cm}^{3} /$ kaynak parçacık) 5 farklı enerji kaynağı için grafiksel örgü hesaplanması ile incelenmiştir.

Incelenen insan kafa modeli, deri, kafatası, kafa hacmi ve tümörden oluşan SNYDER modelidir (ICRU 2000, Snyder et al. 1969). Bu modelde insan kafa yapısı farklı yoğunluk ve hacme sahip 5 farklı bölgeye ayrılmıştır. Şekil 1 (a)'da oluşturulan bu model görülmektedir. Şekil 1 (a)'da görülen kafa modeli, deri (300 bölgesi), kafatası (200 bölgesi), beyin (100 bölgesi), tümör(101 bölgesi) ve hava bulunan dış bölge (400 bölgesi) hücrelerinden oluşturularak temsil edilmiştir. Bu bölgelerde deri, kafatası ve beyin elipsoid şeklinde tasarlanmıştır. Tümör bölgesi ise yarıçapı $2 \mathrm{~cm}$ olan küresel bir yapı olarak tasarlanmıştır.

Şekil 1 (b-f)'de ise grafiksel örgü hesaplaması görülmektedir. Nükleon başına enerjisi $210 \mathrm{MeV} / \mathrm{u}$, $230 \mathrm{MeV} / \mathrm{u}, 250 \mathrm{MeV} / \mathrm{u}, 270 \mathrm{MeV} / \mathrm{u}$, ve $290 \mathrm{MeV} / \mathrm{u}$ olan karbon demetlerinin kafa bölgeleri ve hedef tümör bölgesinde enerji depolanması dağılımları renkli olarak hesaplanmıştır. Kırmızı bölge en yoğun enerji depolanması olan kısımdır. Mavi bölge ise az enerji depolanması olan bölgelerdir. Tümör bölgesine en uygun enerji depolanması $230 \mathrm{MeV} / \mathrm{u}$ enerjili kaynaktan çıkan karbon iyonları vermiştir. Ortalama enerji depolanması Bragg pikini en uygun bu demet enerjisinde vermiştir. Şekil 2'de farklı kaynak karbon enerjilerine sahip demetlerin tümör bölgesinde enerji depolanmasının logaritmik grafiği görülmektedir. Şekil 2'de x-ekseni, tümör bölgesinde karbon iyonlarının sahip olduğu enerji dağılımını göstermektedir. Genel olarak, karbon iyonu enerjilerine karşılık gelen tümör bölgesinde depolanan enerji miktarı verilmiştir. Gelen karbon iyonlarının enerjilerine göre enerji depolanması, 210 $\mathrm{MeV} / \mathrm{u}$ ve $230 \mathrm{MeV} / \mathrm{u}$ demet enerjileri için yaklaşık olarak sabitken 1000-1500 MeV aralığında ani bir düşüş olmuştur. $250 \mathrm{MeV} / \mathrm{u}$ için 1000-1750 MeV arasında, $270 \mathrm{MeV} / \mathrm{u}$ için 1250-2250 MeV aralığında ve $290 \mathrm{MeV} / \mathrm{u}$ enerjili karbon iyonları için 2000-2500 $\mathrm{MeV}$ enerji aralığında pik yaptıktan sonra enerji depolanmasında bir düşüş olmuştur. Kaynaktan belli bir enerji ile çıkan karbon iyonları hedef tümör bölgesine ulaştığında enerjilerinin önemli bir kısmını kaybetmiştir.

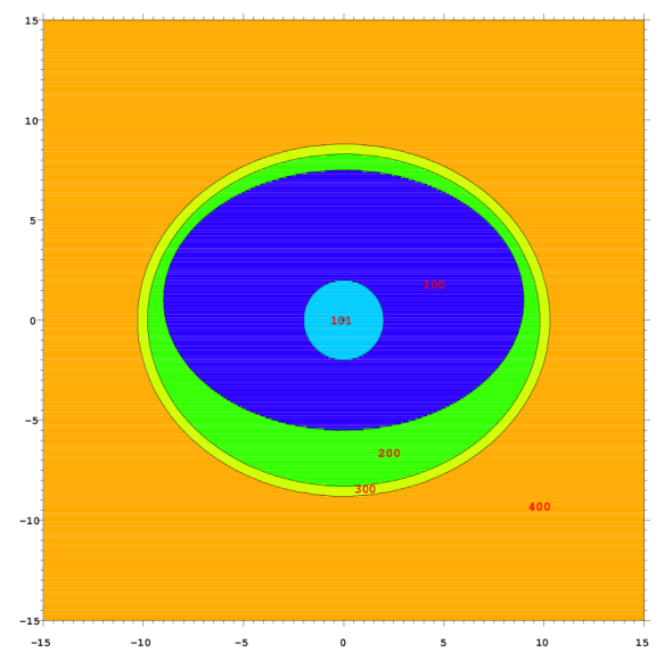

(a) 
Şekil 1. (a) İnsan kafasını oluşturan bölgeler,

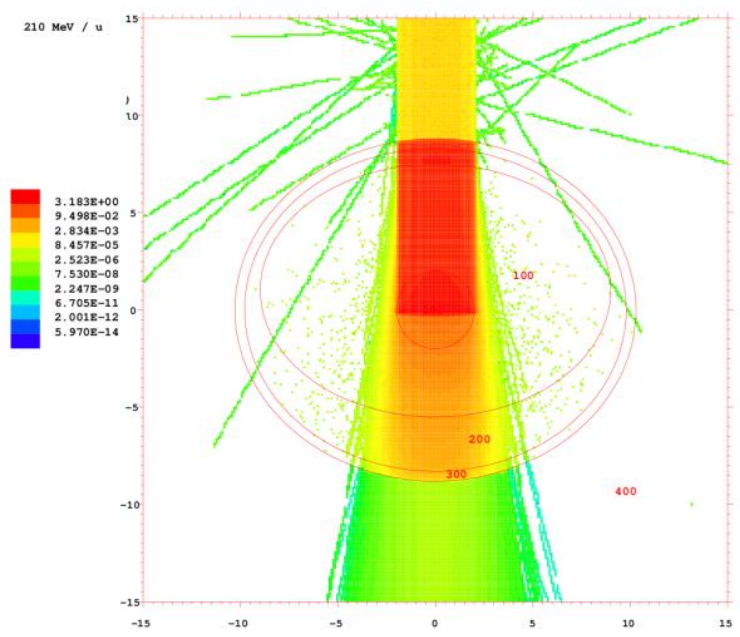

(b)

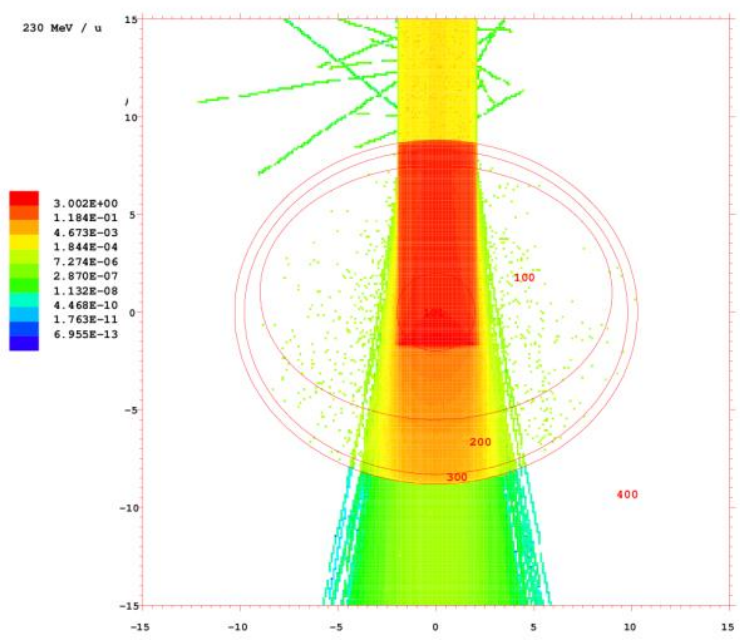

(c)

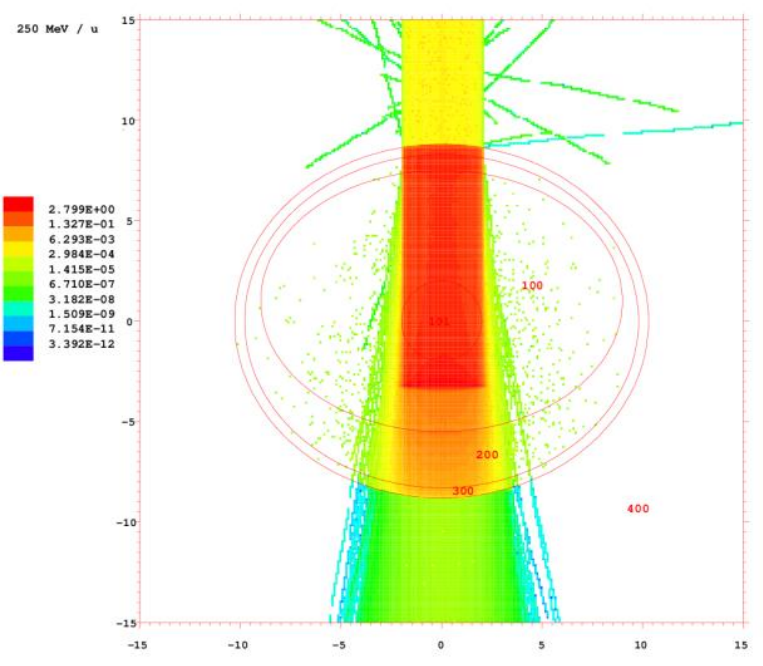

(d)

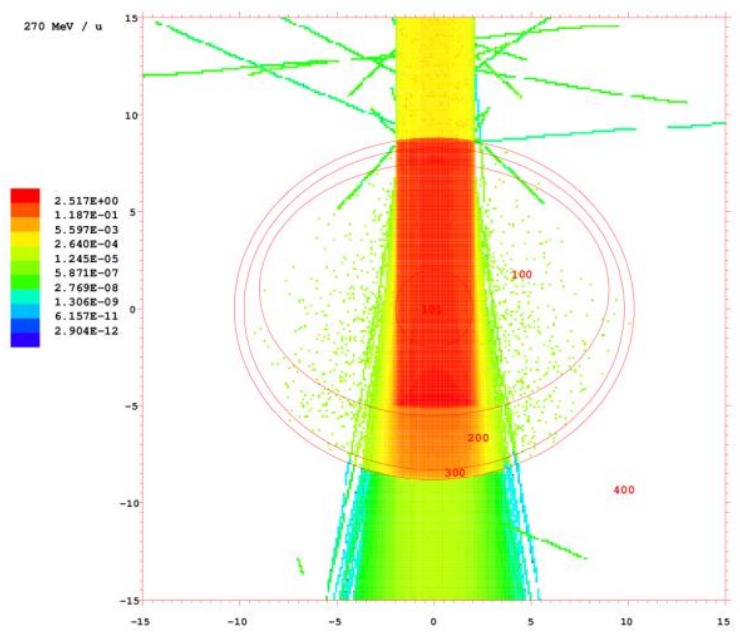

(e)

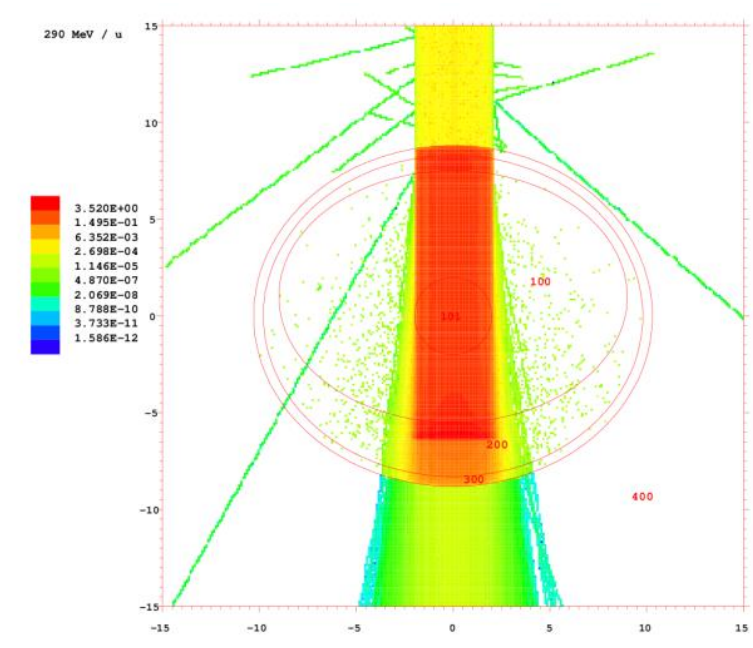

(f)

Şekil 1. (Devam) (b-f) farklı enerjili karbon demetlerinin beyin tümörü bölgesinde oluşturduğu dozların grafiksel örgü hesabı

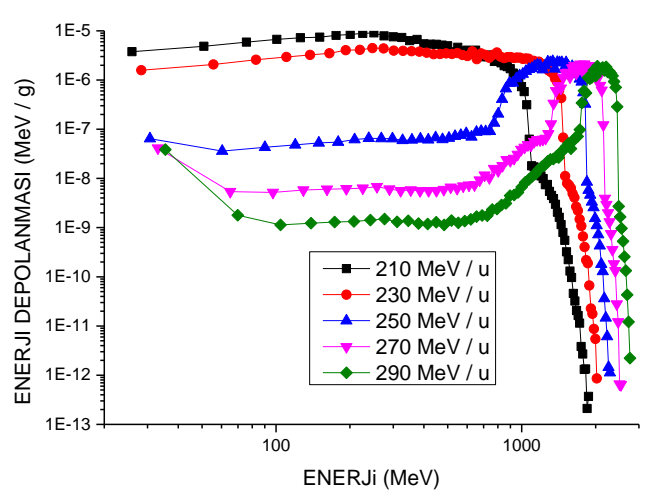

Şekil 2. Karbon demeti enerjilerine göre tümör bölgesinde enerji depolanması 


\section{Tartışma ve Sonuç}

Dünya çapında yaklaşık 70 iyon tedavisi tesisi, ağırlıklı olarak proton ve daha az sayıda ise karbon iyonları kullanarak hastaları tedavi etmektedir. Özellikle Almanya'da bulunan Heidelberg İyon Işın Terapi Merkezi(HIT) gibi senkrotron tabanlı tesisler, yakın zamanda helyum ve oksijen gibi farklı iyon türlerini tedavi amaçlı üretme ve hızlandırma imkanı sunabilecektir(Tessonnier et al. 2018). Bu merkezde Combs ve ark.'nın 260 hasta üzerinde yapmış olduğu primer beyin tümörleri ve kafatası taban bölgesinin belirli tümörleri için proton ve karbon iyon radyoterapisi sonrası klinik sonuçlar, çok düşük yan etkilerle umut verici bir sonuç ortaya koymuştur. Toplam 176 hasta proton (\% 67), 84 hasta karbon iyonları (\% 33) ile tedavi edilmiştir (Combs et al. 2013). Japonya'da ise Saitoh ve ark.'nın karbon iyonları kullanarak baş ve boyun tümörüne sahip 47 hasta için yapmış olduğu çalışmada, 2 ve 5 yıllık genel sağ kalım oranları sırasıyla \% 87.9 ve \% 60.4 bulunmuştur (Saitoh et al. 2017).

Karbon iyonu demetleri, radyasyon hasarını kanser alanına yoğun bir şekilde konsantre hale getiren mükemmel fiziksel özelliklere sahip olduklarından, normal dokulara olan yan etkiler diğer radyasyona kıyasla daha küçüktür. Geleneksel radyoterapiye dirençli kanser tümörlerini bu yolla öldürmek biyolojik olarak daha etkilidir. Doz çok yoğunlaştığından ve tek bir tedavi fraksiyonunun radyasyon dozunun yüksek olması nedeniyle, tedavi süresi diğer radyoterapiden daha kısadır, bu nedenle hastanede harcanan süre azalır ve dolayısıyla normal yaşamda kesinti daha az olur. Protonlar ile karşılaştırıldığında, karbon iyonları, bragg tepesinin ötesinde, karbon iyonları ve doku atomları arasındaki nükleer reaksiyonlar daha yüksek bir aralığa sahip daha açık iyonların üretimine yol açtığından, verilen dozun sıfıra düşmemesi gibi dezavantaja sahiptir. Bu nedenle, bazı hasarlar bragg zirvesinin ötesinde de görülmektedir.

Insan vücudundaki yağ ve kas dokularında en bol bulunan çekirdekler ${ }^{16} \mathrm{O},{ }^{12} \mathrm{C},{ }^{14} \mathrm{~N}$ ve ${ }^{1} \mathrm{H}$, izotoplarıdır. Karbon tedavisinde ${ }^{12} \mathrm{C}$ iyonları bu izotoplarla nükleer reaksiyona girerek ${ }^{18} \mathrm{~F}$ ve ${ }^{24} \mathrm{Na}$ gibi yarı ömrü kısa radyoaktif izotoplar oluşturabilir. Bu yüzden klinik uygulamalardan önce tedavi amaçlı enerji aralığında yüklü ağır iyonların nükleer etkileşimlerinin daha kapsamlı çalışmalara ihtiyaç duyulmaktadır.

\section{Kaynaklar}

Combs, S.E., et al., 2013. Proton and carbon ion radiotherapy for primary brain tumors and tumors of the skull base. Acta Oncologica, 52(7), 1504-1509.

Durante M. and Paganetti H. 2016. Nuclear physics in particle therapy: a review, Reports on Progress in Physics, 79(9), 096702.

Glowa et al., 2017. Carbon ion radiotherapy: impact of tumor differentiation on local control in experimental prostate carcinomas. Radiation Oncology, 12(1), 174.

IAEA TRS 461, 2008. Relative biological effectiveness in ion beam therapy, technical reports series no. 461, Internatıonal Atomic Energy Agency, VIENNA

ICRU Report 63, 2000. Nuclear Data for Neutron and Proton Radiotherapy and for Radiation Protection. International Committee on Radiation Units and Measurements, Bethesda, MD

Johnson, R. P., 2017. Review of medical radiography and tomography with proton beams. Reports on Progress in Physics, 81(1), 016701.

Knäusl, B., et al., 2016. Can particle beam therapy be improved using helium ions? - a planning study focusing on pediatric patients. Acta Oncologica, 55(6), 751-759.

Mein, S., et al., 2018. FRoG-A New Calculation Engine for Clinical Investigations with Proton and Carbon Ion Beams at CNAO. Cancers (Basel). 10(11), 395.

Park, S. H., Kang, J. O., 2011. Basics of particle therapy I: physics. Radiation Oncology Journal, 29(3), 135-146.

Pelowitz, D. B., 2011. MCNPX User's Manual. Version 2.7.0, Los Alamos National Laboratory, LA-CP-1100438.

Rieken, S., et al., 2012. Proton and carbon ion radiotherapy for primary brain tumors delivered with active raster scanning at the Heidelberg Ion Therapy Center (HIT): early treatment results and study concepts. Radiation Oncology, 7(41). 
Resch, A. F., Fuchs, H. and Georg, D., 2017.

Benchmarking GATE/Geant4 for 160 ion beam therapy. Physics in Medicine \& Biology, 62(18):N474N484.

Saitoh, J. ichi, et al., 2017. A Multicenter Study of Carbon -Ion Radiation Therapy for Head and Neck Adenocarcinoma, International Journal of Radiation Oncology, Biology, Physics, 99, 442-449.

Schardt D., Elsässer T. and Schulz-Ertner D. 2010. Heavyion tumor therapy: physical and radiobiological benefits, Reviews of Modern Physics, 82, 383.

Snyder W.S., et al., 1969. Estimates of absorbed fractions for monoenergetic photon sources uniformly distributed in various organs of heterogeneous phantom. Journal of Nuclear Medicine, 3:7-52.

Tessonnier, T., et al., 2018. Proton and Helium Ion Radiotherapy for Meningioma Tumors: A Monte Carlo-based Treatment Planning Comparison. Radiation Oncology, 13(1), 2.

Traini, G., et al., 2017. Design of a new tracking device for on-line beam range monitor in carbon therapy. Physica Medica, 34 (2017), 18-27.

Zhang, R., et al., 2013. Advantages of mcnpx-based lattıce tally over mesh tally in high-speed monte carlo dose reconstruction for proton radiotherapy. Nuclear Technology, 183(1), 101-106.

\section{internet kaynakları}

1- https://www.ptcog.ch (07.03.2018) 